\title{
Oh No, Not Another Framework!
}

\author{
Sensibility, contemplation and craftmanship as a foundation for \\ sustainable development within fashion and textile design
}

\author{
ANNE LOUISE BANG
}

\begin{abstract}
The aim of this paper is to emphasise the relevance and importance of sensibility, contemplation and craftmanship as a foundation for sustainable development driven by fashion and textile design. The paper looks beyond the frameworks and tools that often guide lecturers in higher educational institutions. Within design, we have access to several newly launched and open source frameworks and method collections, but the question is how we prepare educators as well students to critically work with, contribute to and reflect upon sustainable development acting as change agents across disciplines? This position paper suggests and discusses the value of combining disciplinary expertise with cross-disciplinary teamwork. It also suggests that we fully acknowledge and implement this in our teaching and curriculums of fashion and textile designers. The yarn winding technique known from weaving serves as an example to discuss cross-disciplinary mutual understanding in combination with deep disciplinary articulation as a means for sustainable change of the fashion and textile industry.
\end{abstract}

KEYWORDS: Textile and Fashion Design; Sustainable Development, Disciplinary Articulation; Cross Disciplinary Understanding, Sensibility and Contemplation

One of the biggest challenges of working with sustainable development in fashion and textiles is that it is a rather complex subject area. This is caused by the the value chain that ideally includes all steps from production of fibre, yarn and fabric over design and product development to consumption, use, recycling and disposal of worn-out garments. No matter which sustainable actions or solutions the designer suggests, it is often possible to identify some flaws or a fault, something crucial is missing, or there is a tendency to greenwashing even if it was not the intention. From an environmental perspective, it is a burning platform as addressed in the UN Sustainable Development Goal number 12 that calls for a responsible consumption and production. Thus, there is an urgent need to radically change the existing industry, its value chain and its business models as well as the consumption and use patterns in order to get rid of overproduction, overconsumption, underuse and massive amounts of textile waste that goes to the landfill instead of recycling. 
Considering the above, it is relevant to characterise the environmental challenge within fashion and textiles as a wicked problem where the solutions are not true or false but better or worse (Rittel \& Webber, 1973). Furthermore, it is difficult or impossible to formulate rational and clear goals that lead to feasible, viable as well as desirable solutions (IDEO Design Thinking, n.d.). As educators within this subject area, we have to deal with that. Taking the broad and complex value chain into consideration, we need to acknowledge that sustainable development requires collaboration that draws on knowledge and action from many fields and professions moving from a one-eyed narrow and linear way of thinking to a holistic and circular way of designing garments and textile products.

In this position paper, I therefore suggest combining deep disciplinary expertise with crossdisciplinary teamwork, and that we fully acknowledge and implement this in our teaching and curriculums of fashion and textile designers. How do we enable educators as well as students to critically work with, contribute to and reflect upon a sustainable development of the industry? I want to raise a discussion of how we can secure a good foundation for dialogue across fields and professions that acknowledges disciplinary expertise, working with these wicked problems of necessecary change and transition of industry, consumption and use towards a more responsible and sustainable future. To support my discussion, I use an example from textile design and weaving showing how mutual understanding and contemplation can be established through material sensibility and dialogue.

\section{Yarn Winding: Material Sensibility and Dialogue}

Recently, the "Yarn Winding Manifesto" was published by the Danish weaver Astrid Skibsted (Skibsted, 2020). She applies the yarn winding technique to her textile art and as a dialogue tool in collaborative workshops. Yarn winding is a technique used in weaving for planning colour ways, thread density and material combinations. For laymen and other professionals than weavers, yarn winding may simply look like a bunch of threads wrapped around a piece of cardboard and thus appear rather abstract and maybe even useless. I want to use Skibsted's approach to yarn winding as an example of a means for cross-disciplinary understanding rooted in disciplinary skills and knowledge. Even if Skibsted is not working with sustainable change in the way we want the industry to change and live up to the UN Sustainable Development Goals and other goals for sustainability, it is a good example of mutual understanding and articulation across disciplines. I use yarn winding to exemplify a way to think and act, providing the ground for the use of frameworks and method collections in cross-disciplinary project teams.

Skibsted uses yarn winding to establish a dialogue through the materials of the situation. Thereby, the yarn winding experiments become more than random threads. They serve as the soundboard for reflecting on a bigger context. Thereby, Skibsted points to existence, presence and the necessity to be a part of the world instead of just observing it (Pallasmaa, 2005). In 2019 , I had the pleasure of participating in a yarn winding workshop bringing together a group of textile and weaving nerds with professional carreers within teaching, art or industrial design. I experienced how Skibsted invited us to share experiences, simply by asking the group to circulate the yarn windings so that in the end they became a collective piece. But not only did we create a textile expression that told us something about how each of us looked on materials, colours and compositions. Starting a yarn winding with an idea in mind and to see it disrupted and interpreted in a different way by the next person was a simple and yet effective way to kick off a deep conversation while we were working. In our dialogue, we investigated how the Bauhaus Weaver Anni Albers after almost a century is still an inspiring source 
for the profession because of her work but not least her writings in which she uses textiles and weaving as a starting point for sharing her view on the development of the world (Albers, 2017).

The Yarn Winding Manifesto is most of all a sensuous introduction to and a celebration of coloured threads wrapped around a piece of cardboard. It consists of almost 200 plates showing the rich and beautiful world of yarn winding, but there are also a few short texts included in the book. The authors of these were invited to wind together with Skibsted before writing. She insisted on the importance that they 'got the feel for it' before writing. This has led to texts showing a great empathy for the subject and as a reader you can almost feel the yarn while reading. It is about understanding with all senses, it is about contemplation and it is about craftmanship and disciplinary knowledge as an entrance point to mutual understanding across expertises.

In the workshop, Skibsted asked us - the workshop participants - to experiment in the same way that we experiment in our practice as textile designers and artists, namely by reflecting on our work in parallel with carrying it out. Likewise, Donald Schön (1983) suggests ways in which experiments can be conducted as reflection-in-action outside a scientific, controlled environment. In the next section, I will introduce Schön's understanding of having a conversation with the materials of the situation.

\section{Frameworks and Reflection-in-Action}

First, I must admit that I love frameworks, methods, tools and techniques that can assist and support structuring and operationalising my work as a researcher and educator in fashion and textiles design (e.g., Bang, 2013; Bang et al., 2020; Hasling \& Bang, 2016). With the growing focus on sustainable change and green transistion, a large number of open source frameworks, method collections and reports on how to approach sustainability in design has been published (e.g., Ellen MacArthur Foundation \& Ideo, 2017; Fashion Futures 2030, n.d.; Fletcher \& Klepp, 2017; Fletcher \& Tham, 2019; Ræbild \& Hasling, 2018; Simonsen, 2020; The Ten Cards, 2011; Williams, 2019). Add to that traditional textbooks, which mainly focus on tools and techniques such as material technology, construction techniques, pattern construction and/or collection building (e.g., Eberle et al., 2014; Hatch, 2006; Kadolph \& Marcketti, 2016; Strickler, 1991; Wilson, 2001). In my teaching as well as in my research, I have realised that one thing is to have access to proper methods and frameworks, but a real concern might be the educator's mindset (Harsaae \& Bang, 2021). To meet the present environmental and social challenges as an educator in a disruptive and changing age, it is crucial to give the students a disciplinary foundation as well as introduce alternative approaches to the traditional tools and techniques. Traditional tools and techniques must be combined with the newer frameworks and method collections in order to secure that the deep disicplinary knowledge goes hand in hand with generic methods and tools that enable the professional to work as a change agent.

Instead of inventing yet another framework, I suggest looking beyond existing frameworks, method collections and textbooks investigating what constitutes mutual understanding and deep reflection across disciplines and within disciplines. As a design practitioner trained as a weaver, one of my strongest competencies is to reflect in action and react on that reflection. $\mathrm{I}$ do it in silence in my own practice as a designer, educator and researcher, but I also do it outloud when I participate in collaborative projects, in a research team, teach with colleagues, etc. Reflection-in-action as a concept is defined and described by Donald Schön: "When the practitioner reflects-in-action in a case he perceives as unique, paying attention to phenomena and surfacing his intuitive understanding of them, his experimenting is at once

256

Oh no, Not Another Framework!

Futures of Education, Culture \& Nature - Learning to Become 
exploratory, move testing, and hypothesis testing" (Schön, 1983, p. 147). According to Schön, the practitioner can establish a conversation with the materials of a situation due to the backtalk caused by the moves s/he makes in his/her experimentation. In this way, it is possible to go beyond the initial understanding of the given problem or challenge. Reframing the problem based on the (design) activity constitutes a hypothesis about the situation. It can be argued that having a conversation with the materials of a situation not only shapes the situation, it also shapes the practitioner's models and appreciations. The practitioner understands the situation by trying to change it (Schön, 1983).

Skibsted uses yarn winding as a tangible dialogue tool encouraging the workshop participants to reflect-in-action by asking them to let the yarn windings circulate. Thereby, Skibsted uses the yarn winding as an informal but direct entrance point to foster deep dialogue about the subject. Receiving an unfinished yarn winding and having to continue working on it without knowing the design idea and rationale behind it demands a lot of effort from the participants. With Schön's words, they are reflecting-in-action by having a conversation with the materials of the situation.

\section{Cross-Disciplinary Understanding: The Silent Game}

It is reasonable to argue that reflection-in-action is deeply integrated in the way we practice our practice. However, it is also possible to consciously establish a space for reflection-in-action. The Silent Game was invented by John Habraken and fellows in 1987 (Habraken et al., 1987). It was later used at the course 'Learning to Design and Design for Learning' at MIT in the early 1990es (Schön, 1993). Schön describes the learning from the game in this way: "The design process opens up possibilities for surprise that can trigger new ways of seeing things, and it demands visible commitments to choices that can be interrogated to reveal underlying values, assumptions, and models of phenomena" (Schön, 1993, p. 60). This means that the Silent Game is played on two levels simultaneously. Firstly, it can illustrate different players' interpretation of prototypes. Secondly, it shed lights on the communication between the players.

At MIT, the game was played by two active players and one observer. The players were design students. The game pieces were a selection of elements from toy construction systems. Player A makes a move by setting up some pieces according to a self-made rule, and player B must make a move that shows the understanding of the rule. The game thus moves back and forth between the two players while player $B$ as well as the observer tries to understand the rule set up by player $A$. Considering that this takes place in complete silence, the example shows that it takes an effort to establish communication and mutual understanding even between students from the same speciality programme (Schön, 1993).

However, designed for exercising relational skills in design, the Silent Game can be played in a variety of ways, and Habraken argues that it is an "excellent introduction to interactive plays" (Habraken, 2015, p. 1). In my experience, playing the Silent Game at a PhD course, it is not connected to a certain discipline or disciplinary way of thinking. It simply lays the ground for and supports a dialogue across disciplines. The players' mindset will be influenced by their professionalism and disciplinary expertise and that sets the direction for the rules that are made up by player A when the game begins, and the way player B understands it and makes the next move.

The Silent Game is not a framework. It is rather a means to reflection-in-action between the players, with the purpose to achieve mutual understanding and learn about ways of thinking and communicating. For this reason, I use the Silent Game to explain and generalize part 
of what is happening in Skibsted's yarn winding experiments. Making yarn winding with Skibsted fosters a dialogue about the subject in question. Thus, the yarn and the cardboard function as the elements of a Silent Game that guides us towards mutual understanding even though the yarn winding was not performed in silence.

If the Silent Game represents the dialogue across different approaches to textiles and weaving, how can we then discuss disciplinary expertise and ways in which to communicate it and invite other professionals to participate, contribute and understand the dialogue?

\section{Disciplinary Articulation: Tactile Blueprints}

In my attempt to argue for the potential that lies in a cross-disciplinary mutual understanding that includes a professional disciplinary articulation and vocabulary, I will take a closer look at textile design and weaving since this is the example used in this paper. I have exemplified how Skibsted is creating a space for mutual understanding with her yarn winding exercises. But what is going on from a disciplinary point of view?

With the yarn winding example in mind, it is relevant to look towards the writings of the Bauhaus weaver Anni Albers and her thoughts about building a professional vocabulary or repertoire (Albers, 2017). Albers was educated in the Bauhaus Weaving Workshop, and later she was one of the founders of the Black Mountain College in USA (Weltge, 1993). Anni Albers was a highly skilled weaver, and, in addition to that, she wrote a series of essays about textiles and weaving and the way she looked at societal development in general. I bring in Albers to better understand the disciplinary communication that lies in the yarn windings, and how it connects with a cross-disciplinary understanding.

In her essay about tactile sensibility, Albers uses the phrases "experiments in articulation", "common words", "sensibility to respond", "a receptive mind" and "to discover meaning" (Albers, 2017, p. 44-47). I will argue that these phrases reflect the same thoughts expressed in the concept of reflection-in-action as well as the reflexive and mutual understanding described in the Silent Game. Albers is not expressing an interest in silence, on the contrary she is interested in building vocabularies and knowledge about sensibility and what she refers to as the medium of tactility. In the essay about tactile sensibility, she is discussing the surface quality of materials versus the inner structure and the way in which they combine and constitute the full tactile experience of textiles. Albers expresses a frustration of the modern world and the way we have been giving up on handling raw materials in our everyday life. She argues that we have grown increasingly insensitive in our perception of touch (Albers 2017). Therefore, she introcudes the tactile blueprints - I call it rapid prototypes - for weave patterns using corn, metal scrap, straw and other household materials glued on paper to resemble structures of weave patterns. "These varied experiments in articulation are to be understood not as an end in themselves but merely as a help to us adding new terms to the vocabulary of tactile language" (Albers, 2017, p. 47). In this way, Albers demonstrates what might be termed as craftmanship of the professions.

Drawing on the Silent Game and the research in mutual understanding and communication by Schön and Habraken et al. and combining it with Albers' work on a disciplinary and tactile vocabulary, I argue that Skibsted's yarn windings can be seen as a means to cross-disciplinary understanding through disciplinary articulation. In the concluding remarks, I will briefly return to the education of future fashion and textile designers as change agents that are prepared to take responsibility and participate in changing the existing linear fast fashion and textile industry into a circular and more holistically-oriented business that takes sustainability and our common future seriously. 


\section{Concluding Remarks}

The intention with this paper is to fuel a dialogue about the necessity of sensibility, contemplation and craftmanship as a necessary foundation for sustainable change of the fashion and textile industry. I have suggested and argued for the value of combining deep disciplinary expertise with cross-disciplinary teamwork, and that we fully acknowledge and implement this in our teaching and curriculums of fashion and textile designers. I use the yarn winding technique from weaving as an example that fosters disciplinary articulation and mutual understanding across disciplines and comptences backing my argumentation with research from the fields of design and textile design. My aim is to enable fashion and textile designers to contribute to a fundamental, responsible and sustainable change of society and especially the fashion and textile industry. As a designer, you can have splendid frameworks, but you fail if you are not able to contribute to creating a space for working together across disciplines with various competencies and knowledge. This puts a heavy pressure on the designers but also on the educators that must rethink the disciplinary tools and methods creating a learning environment that is not counterproductive to change.

\section{Literature}

Albers, A. (2017). On Weaving - New Expanded Version. Princetown University Press.

Bang, A. (2013). The Repertory Grid as a Tool for Dialog about Emotional Value of Textiles. Journal of Textile Design Research and Practice, 1(1), 9-26. doi:10.2752/175183513X13772670831038

Bang, A., Kappel, E. \& Mikkelsen, M. (2020). The Tripod Approach: A pedagogical Tool for Concept Development in Fashion and Textile Design. In: 22nd International Conference on Engineering and Product Design Education, Herning, Denmark, 10-11 September 2020.

Eberle, H., Gonser, E., Hermeling, H., Hornberger, M., Kilgus, R., Kupke, R., Menzer, D., Moll, A. \& Ring, W. (2014). Clothing Technology ...from fibre to fashion. Sixth Edition. HaanGruiten: Verlag Europa-Lehrmittel.

Ellen MacArthur Foundation \& Ideo. (2017). The Circular Design Guide. https://www.circulardesignguide.com [Accessed 01052021]

Fashion Futures 2030 (n.d.). https://www.fashionfutures2030.com/scenarios/home [Accessed 01052021]

Fletcher, K. \& Klepp, I. (eds.) (2017). Opening up the Wardrobe: A Methods Book. Novus.

Fletcher, K. \& Tham, M. (2019). Earth Logic - Fashion Action Research Plan. https://earthlogic.info [Accessed 31012021]

Habraken, J. (2015). http://designplaybook.org/wp-content/uploads/2014/12/TDW\%20SILENT\%20GAMEa13.pdf [Accessed 30042021]

Habraken, J., Gross, M., Anderson, Dale, Hamdi, Palleroni, Saslaw \& Wang. (1987). Concept Design Games. Book two: Playing. Massachusetts: Massachusetts Institute of Technology.

Hasling, K. \& Bang, A. (2016). How associative material characteristics create textile reflection in design education. In: Journal of Textile Design Research and Practice, Vol 3, 2016, pp. 2746. 10.1080/20511787.2015.1210916

Bang, A. \& Harsaae, M. (2021). Old Wine in new Bottles - An Alternative Didactic Approach to Tools Used in Fashion Design. In: 23th International Conference on Engineering and Product Design Education, Herning, Denmark, 9-10 September 2021.

Hatch, K. (2006). Textile Science. Revised edition. Apex: Tailored Text Custom Publishing.

IDEO Design Thinking (n.d.). https://designthinking.ideo.com [Accessed 01052021]

259

Anne Louise Bang

Futures of Education, Culture \& Nature - Learning to Become 
Kadolph, S. \& Marcketti, S. (2016). Textiles. Twelfth Edition. Boston: Pearson.

Pallasmaa, J. (2005). The eyes of the Skin. Architecture and the Senses. Chichester: John Wiley \& Sons Ltd.

Rittel, H., \& Webber, M. (1973). Dilemmas in a General Theory of Planning. In: Policy Sciences, 4, 155-169.

Schön, D. (1993). Learning to Design and Designing to Learn. In: Nordic Journal of Architectural research, 1993:1, pp. 55-70.

Simonsen, R. (2020). Fashion at a Turning Point. Implementing the Sustainable Development Goals in Education and Business, Copenhagen: Copenhagen School of Design and Technology.

Skibsted, A. (2020). The Yarn Winding Manifesto. Aarhus: Skibsted.

Strickler, C. (1991). Weaver's book of 8-Shaft Patterns from the friends of handwoven. Loveland: Interweave Press Inc.

The TEN Cards (2011). https://www.circulardesign.org.uk/tools/ [Accessed 01052021]

Ræbild, U., \& Hasling, K., (2018). Sustainable Design Cards: A Learning Tool for Supporting Sustainable Design Strategies, In: Niinimäki, K. (Ed.). Sustainable Fashion in a Circular Economy. Helsinki: Aalto University. https://sustainabledesigncards.dk [Accessed 01052021]

Weltge, S. (1993). Bauhaus Textiles. Women artists and the weaving workshop. London: Thames and Hudson Ltd.

Williams, D. (ed.) (2019). Education and Research - The Benchmark Report. Fashion Seeds Fashion Societal, Economic \& Environmental Design-led Sustainability. https://www.sustainable-fashion.com/fashion-seeds [Accessed 01052021]

Wilson, J. (2001). Handbook of textile design. Cambridge: CRC Press. 